\title{
Late-life depression and mortality: influence of gender and antidepressant use
}

Joanne Ryan, Isabelle Carriere, Karen Ritchie, Robert Stewart, Gwladys Toulemonde, Jean-François Dartigues, Christophe Tzourio and Marie-Laure Ancelin

\section{Background}

Depression may increase the risk of mortality among certain subgroups of older people, but the part played by antidepressants in this association has not been thoroughly explored.

\section{Aims}

To identify the characteristics of older populations who are most at risk of dying, as a function of depressive symptoms, gender and antidepressant use.

\section{Method}

Adjusted Cox proportional hazards models were used to determine the association between depression and/or antidepressant use and 4-year survival of 7363 communityevaluated using a standardised psychiatric examination based on DSM-IV criteria and depressive symptoms were dwelling elderly people. Major depressive disorder was

assessed using the Center for Epidemiological StudiesDepression scale.

\section{Results}

Depressed men using antidepressants had the greatest risk of dying, with increasing depression severity corresponding to a higher hazard risk. Among women, only severe depression in the absence of treatment was significantly associated with mortality.

\section{Conclusions}

The association between depression and mortality is genderdependent and varies according to symptom load and antidepressant use.

\section{Declaration of interest} None.

\section{Depression measures}

Late-life depression is often underdiagnosed and undertreated; when treatment is given, it is often inappropriate. ${ }^{2}$ Depression is associated with higher comorbidity, ${ }^{3}$ and may increase the risk of mortality, ${ }^{4-8}$ although this has not been found consistently. ${ }^{9-13}$ This variability can be partly explained by the large heterogeneity between the studies in terms of the populations (community $v$. clinical samples), the method of depression assessment (clinical or standardised examination $v$. self-evaluation) and the type of depression diagnosed (major or minor depression, depressive symptoms or 'psychiatric distress'). The limited extent of covariate adjustment has also influenced the findings, ${ }^{12-14}$ with few community-based studies controlling for antidepressant use. ${ }^{12,13}$

The objective of our study was to examine the association between depression and mortality in a large community-based elderly population, which permitted the examination of a wide range of clinical profiles and extensive adjustment for confounding factors. Analysis of gender differences and the impact of antidepressant use were also considered.

\section{Method}

\section{Study population}

The data used for this analysis were derived from the Three City Study (3C), an ongoing multicentre longitudinal study involving the French cities of Bordeaux, Dijon and Montpellier. ${ }^{15}$ Recruitment of the cohort took place between 1999 and 2001, with eligible participants (aged over 65 years and non-institutionalised) randomly selected from the electoral rolls in the three cities. The study protocol was approved by the ethical committee of the University Hospital of Kremlin-Bicêtre (France) and written informed consent was obtained from all participants. Participants were interviewed by trained staff and underwent a number of clinical examinations at baseline and every 2 years thereafter.
The Mini International Neuropsychiatry Interview (MINI) ${ }^{16}$ a standardised psychiatric examination which has been validated in the general population, was used for the diagnosis of current major depressive disorder, according to DSM-IV criteria. ${ }^{17}$ Severity of depressive symptoms was assessed using the 20-item Center for Epidemiology Studies-Depression scale (CES-D); ${ }^{18}$ information was also gathered on the participants' history of major depressive episodes throughout their lifetime, to identify those with incident depression (one episode) $v$. recurrent depression (two or more episodes).

For the analysis, participants were classified into one of three groups. 'Severe depression' included participants with a current major depressive disorder or a CES-D score of 23 or over, allowing for the fact that some participants with severe symptoms did not reach DSM classification criteria, most commonly because of the duration of symptoms. 'Mild depression' was defined as a CES-D score between 16 and 22 and 'no depression' included participants with a CES-D score lower than 16 .

Current use of antidepressants was validated by presentation of the prescription or the medication itself and the type of medication was noted according to the World Health Organization's Anatomical Therapeutic Chemical (ATC) classification. ${ }^{19}$

\section{Mortality}

The follow-up time for this analysis was 4 years, with a median of 3.7 years for both men and women. For the participants who died during this period, information on the exact date and cause of death was determined respectively from death registries and medical records (based on the ICD-10). ${ }^{20}$ All-cause mortality was the principal outcome defined for this analysis; however, cause-specific mortality was also examined. 


\section{Other measures}

At inclusion, information was obtained on socio-demographic and lifestyle characteristics, as well as overall health. Participants were classified as disabled if they were unable to complete at least two tasks from either the Instrumental Activities of Daily Living $(\mathrm{IADL})^{21}$ or the Activities of Daily Living (ADL) ${ }^{22}$ scales. Cognitive function was assessed using the Mini-Mental State Examination (MMSE). ${ }^{23}$ Within each centre, participants scoring less than the 10th percentile for their age (four groups) and education level (four groups) were classified as cognitively impaired. This method of classifying cognitive impairment, compared with that based on an unadjusted MMSE score below 26, did not change the results of the study.

Detailed medical questionnaires were used to obtain information on history of vascular diseases (including angina pectoris, myocardial infarction, stroke, cardiovascular surgery, bradycardia or palpitations), other chronic illnesses (asthma, diabetes; fasting glucose $\geqslant 7.2 \mathrm{mmol} / \mathrm{l}$ or reported treatment), hypercholesterolaemia (total cholesterol $\geqslant 6.2 \mathrm{mmol} / \mathrm{l}$ ), hypertension (resting blood pressure $\geqslant 160 / 95 \mathrm{mmHg}$ or treated) and thyroid problems) and diagnoses of cancer within the past 2 years. Participants were classified as having comorbidity if they had one or more of these illnesses. Hospitalisation for a non-traumatic illness within the past 2 years was also used as a measure of health status.

The multivariate analysis controlled for all covariates that have been reported to be confounding factors in relation to depression and mortality; ${ }^{4,6,12,14}$ age (continuous), education level $(<12 v$. $\geqslant 12$ years of schooling), living situation (alone $v$. with others), current alcohol consumption (binary: $<24 v$. $\geqslant 24$ g per day), current smoking status (binary: $<200 v$. $\geqslant 200$ cigarettes per year), body mass index (BMI; $\leqslant 18,18-30$ or $\geqslant 30 \mathrm{~kg} / \mathrm{m}$ ), disability (yes/no), cognitive impairment (yes/no), comorbidity (yes/no) and recent hospitalisation (yes/no).

\section{Statistical analysis}

Two-tailed chi-squared tests were used to compare the baseline characteristics between men and women and to determine differences in unadjusted characteristics between participants with and without depressive symptoms, or between antidepressant users and non-users. Cox proportional hazards analysis was used to model the risk of mortality during the follow-up period. The age of participants at inclusion was taken as the basic timescale ${ }^{24}$ to account for the non-proportionality in risk of mortality with age among the elderly, ${ }^{4,14}$ and Cox models with delayed entry were used. To estimate the risk associated with current depression or antidepressant use, models were generated with reference to non-depressed (no major depression and CES-D score $<16$ ) or non-treated participants respectively. When the combined effects of depression and antidepressant treatment were examined, participants who were currently neither depressed nor using treatment were the reference group.

Unadjusted models were initially constructed for each of the factors of interest, controlling only for study centre. Owing to the statistically significant interactions between gender and both depression (mild: $z=-0.76$, d.f. $=1, P=0.004$; severe: $z=-1.34$, d.f. $=1, P<0.001)$ and antidepressant use $(z=-1.44$, d.f. $=1$, $P<0.001)$, all subsequent analysis was undertaken separately for men and women. Multivariate analysis was used to determine the hazard associated with current depression and/or antidepressant treatment, while adjusting for the potential confounding factors and stratifying by gender. There was no indication of collinearity between any of the covariates and no statistically significant interaction terms in the adjusted models. The software
SAS version 9.1 for Windows was used for all of the statistical analysis and the significance level was $P<0.05$.

\section{Results}

\section{Study population}

Of the 9294 participants initially recruited in the 3C Study, 1922 participants were excluded from this analysis because they had missing data for some of the depression and/or confounding variables. A further 9 participants were lost to follow-up, leaving 7363 for this analysis. Compared with the analysed sample, those not included in this analysis were more likely to be older $\left(\chi^{2}=162\right.$, d.f. $=1, P<0.001)$, live alone $\left(\chi^{2}=39.8\right.$, d.f. $\left.=1, P<0.001\right)$, have lower education $\left(\chi^{2}=3.99\right.$, d.f. $\left.=1, P=0.05\right)$, be underweight $\left(\chi^{2}=8.9\right.$, d.f. $\left.=1, P=0.003\right)$, have disabilities $\left(\chi^{2}=398\right.$, d.f. $=1$, $P<0.001)$ and cognitive impairment $\left(\chi^{2}=63.9\right.$, d.f. $=1$, $P<0.001)$, have comorbidity $\left(\chi^{2}=12.9\right.$, d.f. $\left.=1, P<0.001\right)$ and to have been hospitalised recently $\left(\chi^{2}=12.4\right.$, d.f. $\left.=1, P<0.001\right)$. They were also more likely to be using antidepressants $\left(\chi^{2}=25.8\right.$, d.f. $\left.=1, P<0.001\right)$, to be depressed $\left(\chi^{2}=11.1\right.$, d.f. $=2$, $P=0.004)$ and to have died during the follow-up period $\left(\chi^{2}=156\right.$, d.f. $\left.=1, P<0.001\right)$. There was, however, no difference in the gender ratios of participants included in the analysis and those who were not.

Baseline characteristics of the 7363 participants in the analysed sample are summarised in Table 1 . The majority were female $(60.8 \%)$ with a mean age of 74 years (range 65-93). With the exceptions of centre, obesity and adjusted MMSE score, men and women differed significantly in all of the covariates examined.

\section{Prevalence and correlates of depression}

The prevalence of severe depression (major depressive disorder or CES-D $\geqslant 23$ ) was $10.2 \%$, including $1.8 \%$ diagnosed with major depressive disorder, whereas that of mild depression (CES-D 16-22) was $12.1 \%$ (Table 2 ). Women had a significantly higher prevalence of depression than men and were more than twice as likely to use antidepressants. Among those using antidepressants, over half were taking selective serotonin reuptake inhibitors (SSRIs) and a relatively high number used tricyclic antidepressants.

Compared with the non-depressed group, those with either mild or severe depression were more likely to live alone $\left(\chi^{2}=139\right.$, d.f. $\left.=2, P<0.001\right)$, have disability $\left(\chi^{2}=46.5\right.$, d.f. $=2$, $P<0.001)$, cognitive impairment $\left(\chi^{2}=43.6\right.$, d.f. $\left.=2, P<0.001\right)$ and comorbidity $\left(\chi^{2}=14.3\right.$, d.f. $\left.=2, P<0.001\right)$. Women with depression were also of lower education $\left(\chi^{2}=15.4\right.$, d.f. $=2$, $P<0.001)$ and were more likely to have been hospitalised recently $\left(\chi^{2}=9.24\right.$, d.f. $\left.=2, P=0.01\right)$, whereas men with depression were older $\left(\chi^{2}=10.5\right.$, d.f. $\left.=2, P=0.005\right)$.

\section{Incidence and correlates of mortality}

The total follow-up time for the study was 26165 person-years and during this period 380 participants (5.2\%) died, with a higher proportion of the deaths among men (7.5\%) than women (3.7\%). Recent hospitalisation $\left(\chi^{2}=37.9\right.$, d.f. $\left.=1, P<0.001\right)$, comorbidity $\left(\chi^{2}=24.6\right.$, d.f. $\left.=1, P<0.001\right)$ and disability $\left(\chi^{2}=83.9\right.$, d.f. $=1$, $P<0.001)$ were all significantly associated with mortality in both men and women, as was increasing age $\left(\chi^{2}=82.4\right.$, d.f. $=1$, $P<0.001)$. Cognitive impairment $\left(\chi^{2}=8.8\right.$, d.f. $\left.=1, P=0.003\right)$ and current smoking $\left(\chi^{2}=8.05\right.$, d.f. $\left.=1, P=0.005\right)$ were associated with mortality in men only. Alcohol consumption, educational level, living alone and BMI were not significantly associated with mortality, but were retained in the adjusted models because of their correlation with mortality at the $20 \%$ significance level and 
Table 1 Baseline characteristics of the sample: men $v$. women $(n=7363)$

\begin{tabular}{|c|c|c|c|c|}
\hline \multirow[b]{2}{*}{ Characteristic } & \multirow[b]{2}{*}{ Men $(n=2886) \%$} & \multirow[b]{2}{*}{ Women $(n=4477) \%$} & \multicolumn{2}{|c|}{ Test for gender difference } \\
\hline & & & $\chi^{2}$ (d.f.) & $P$ \\
\hline$\geqslant 75$ years old & 39.2 & 42.8 & $9.2(1)$ & 0.002 \\
\hline$\geqslant 12$ years schooling & 46.1 & 34.3 & $102.6(1)$ & $<0.001$ \\
\hline Living alone & 13.1 & 47.8 & $940.1(1)$ & $<0.001$ \\
\hline Recently hospitalised & 13.6 & 10.8 & $13.1(1)$ & $<0.001$ \\
\hline Disability & 1.5 & 2.7 & $10.4(1)$ & 0.001 \\
\hline Comorbidity $^{a}$ & 47.5 & 45.1 & $4.0(1)$ & 0.05 \\
\hline Cognitive impairment (MMSE <10th percentile) & 7.1 & 7.0 & $0.01(1)$ & 0.9 \\
\hline Current heavy drinker ( $\geqslant 24$ g per day) & 33.6 & 4.1 & $1156.2(1)$ & $<0.001$ \\
\hline Current regular smoker ( $\geqslant 200$ cigarettes per year) & 48.4 & 9.5 & $1424.9(1)$ & $<0.001$ \\
\hline Underweight (BMI $\leqslant 18$ kg/m) & 0.4 & 1.7 & $26.0(1)$ & $<0.001$ \\
\hline Obese $(\mathrm{BMl} \geqslant 30 \mathrm{~kg} / \mathrm{m})$ & 12.4 & 13.6 & $2.3(1)$ & 0.1 \\
\hline Centre & & & $3.1(2)$ & 0.2 \\
\hline Bordeaux & 24.9 & 25.0 & & \\
\hline Dijon & 50.6 & 52.2 & & \\
\hline Montpellier & 24.5 & 22.8 & & \\
\hline
\end{tabular}

because previous reports suggest that they confound the depression-mortality association.

\section{Associations between mortality and depression severity or antidepressant use}

We first evaluated the separate effects of depression and antidepressant use on 4-year survival. For men, there was an apparent severity-dependent association between depression and mortality (Table 3). Compared with non-depressed men at inclusion, a higher percentage of men with mild depressive symptoms died during follow-up and the percentage of those with severe depression who died was even higher. In site-adjusted Cox models depression severity was positively associated with mortality risk. In models adjusted for a range of covariates a similar trend was seen, but only severe depression remained significantly associated with mortality. For men taking antidepressants, the percentage of deaths was almost three times that for men not receiving such treatment. This corresponded with a significantly increased mortality risk for antidepressant users in the univariate Cox analysis, which remained significant after adjustment for covariates. There was no difference in mortality risk according to type of antidepressant treatment.

In contrast, among women the overall risk associated with depression was less marked, and similar effects were seen regardless of depression severity (Table 4). Mild and severe depression were significantly associated with mortality in univariate analysis, with women having approximately one and a half times the risk of dying during follow-up compared with non-depressed women. After multivariate adjustment the risk associated with depression remained similar in strength, although reduced in significance for both mild and severe depression. Antidepressant use was not

Table 2 Depression characteristics of the sample at baseline: men $v$. women

\begin{tabular}{|c|c|c|c|c|}
\hline & \multirow[b]{2}{*}{ Men $(n=2886) \%$} & \multirow[b]{2}{*}{ Women $(n=4477) \%$} & \multicolumn{2}{|c|}{ Test for gender difference } \\
\hline & & & $\chi^{2}$ (d.f.) & $P$ \\
\hline \multicolumn{3}{|l|}{ Depression severity } & $236.6(2)$ & $<0.001$ \\
\hline No depression & 86.9 & 71.9 & & \\
\hline Mild depression ${ }^{a}$ & 8.1 & 14.6 & & \\
\hline Severe depression ${ }^{b}$ & 5.0 & 13.5 & & \\
\hline Uses antidepressants & 3.7 & 8.5 & $64.8(1)$ & $<0.001$ \\
\hline \multicolumn{3}{|l|}{ Depression severity and antidepressant use } & $269.1(5)$ & $<0.001$ \\
\hline No depression/no antidepressant & 84.8 & 68.1 & & \\
\hline No depression/uses antidepressant & 2.1 & 3.8 & & \\
\hline Mild depression/no antidepressant & 7.4 & 12.9 & & \\
\hline Mild depression/uses antidepressant & 0.7 & 1.7 & & \\
\hline Severe depression/no antidepressant & 4.0 & 10.4 & & \\
\hline Severe depression/uses antidepressant & 1.0 & 3.1 & & \\
\hline \multicolumn{3}{|l|}{ Type of antidepressant ${ }^{\mathrm{c}}$} & $1.21(2)$ & 0.6 \\
\hline Tricyclic antidepressants & 24.1 & 19.4 & & \\
\hline SSRIS & 50.9 & 55.2 & & \\
\hline Other antidepressants & 25.0 & 25.4 & & \\
\hline \multicolumn{5}{|c|}{$\begin{array}{l}\text { SSRI, selective serotonin reuptake inhibitor. } \\
\text { a. Participants with a Center for Epidemiology Studies-Depression (CES-D) score }<23 \text { but above the cut-off for clinically significant depressive symptoms ( } \geqslant 16 \text { ). } \\
\text { b. Participants with a current major depressive disorder or a CES-D score of } \geqslant 23 \text {. } \\
\text { c. Values are percentages of those using antidepressants ( } 108 \text { men, } 382 \text { women). }\end{array}$} \\
\hline
\end{tabular}



Table 3 Cox proportional hazard models for the risk associated with depression or antidepressant use among elderly men
$(n=2886)$

\begin{tabular}{|c|c|c|c|c|c|c|c|}
\hline & \multirow[b]{2}{*}{ Deaths $(n=215) \%$} & \multicolumn{3}{|c|}{ Unadjusted $^{a}$} & \multicolumn{3}{|c|}{ Adjusted $^{\mathrm{b}}$} \\
\hline & & $\mathrm{HR}(95 \% \mathrm{Cl})$ & $\chi^{2}($ d.f. $=1)$ & $P$ & $\operatorname{HR}(95 \% \mathrm{Cl})$ & $\chi^{2}($ d.f. $=1)$ & $P$ \\
\hline \multicolumn{8}{|l|}{ Depression severity } \\
\hline No depression & 6.7 & 1 & & & 1 & & \\
\hline Mild depression ${ }^{c}$ & 11.1 & $1.5(1.0-2.3)$ & 3.65 & 0.05 & $1.5(1.0-2.2)$ & 3.03 & 0.09 \\
\hline Severe depression ${ }^{d}$ & 15.3 & $2.8(1.8-4.4)$ & 20.34 & $<0.001$ & $2.5(1.6-4.0)$ & 15.40 & $<0.001$ \\
\hline \multicolumn{8}{|l|}{ Antidepressant use } \\
\hline No & 7.0 & 1 & & & 1 & & \\
\hline Yes & 20.4 & $2.8(1.8-4.4)$ & 18.56 & $<0.001$ & $2.2(1.4-3.5)$ & 10.88 & 0.001 \\
\hline \multicolumn{8}{|l|}{ Antidepressant type } \\
\hline No treatment & 7.0 & 1 & & & 1 & & \\
\hline TCAS & 30.8 & $2.6(1.1-6.4)$ & 4.56 & 0.03 & $2.4(1.0-6.0)$ & 3.76 & 0.05 \\
\hline SSRIS & 16.4 & $2.3(1.2-4.4)$ & 6.54 & 0.01 & $1.9(1.0-3.7)$ & 3.70 & 0.05 \\
\hline Other & 18.5 & $2.8(1.3-5.9)$ & 7.89 & 0.005 & $2.5(1.2-5.3)$ & 5.51 & 0.02 \\
\hline $\begin{array}{l}\text { HR, hazard ratio; SSRI, sele } \\
\text { a. Adjusted for centre. } \\
\text { b. Adjusted for centre, educ } \\
\text { c. Participants with a Cente } \\
\text { d. Participants with a curre }\end{array}$ & $\begin{array}{l}\text { reuptake inhibitor; TCA, } \\
\text { us, cognitive impairment, } \\
\text { ogy Studies-Depression } \\
\text { ssive disorder or a CES-L }\end{array}$ & $\begin{array}{l}\text { lic antidepressar } \\
\text { alcohol consump } \\
\text { D) score }<23 \text { b } \\
\text { re } \geqslant 23 \text {. }\end{array}$ & $\begin{array}{l}\text { regular smoking } \\
\text { ve the cut-off } f\end{array}$ & $\begin{array}{l}\text { isability, rec } \\
\text { clinically sig }\end{array}$ & $\begin{array}{l}\text { spitalisation, com } \\
\text { nt depressive syn }\end{array}$ & $\begin{array}{l}\text { ty, underweight } \\
\text { s }(\geqslant 16) \text {. }\end{array}$ & d obesity. \\
\hline
\end{tabular}

associated with 4-year survival in either univariate or multivariate analysis, with a similar percentage of women dying in the group taking antidepressants and in the group that did not.

\section{Combined effects of depression and antidepressant use}

To investigate further the association between depression and mortality, participants were then grouped according to depression severity and use of antidepressants (Table 5). Overall there was little change in the significance of the associations found between the univariate and multivariate analysis, with relatively minor differences in the hazard ratios.

Among men, the largest mortality risk was seen in the group with severe depression who were taking antidepressants, and there was also an increased mortality risk for those taking antidepressants who had mild depressive symptoms. In contrast, nondepressed men using antidepressants did not have an increased mortality risk. For the men who were not using antidepressants, minor depression was not associated with 4-year survival, but severe depression appeared to increase risk, just failing to reach significance.

When we considered separately the small number of men with current major depression (diagnosed using the MINI), similar results were obtained to those found in the severe depression group. Men taking antidepressants had a significantly increased risk of dying (adjusted $\mathrm{HR}=6.2,95 \%$ CI $2.2-17.3 ; \chi^{2}=12.0$, d.f. $=1, P<0.001)$ and there was also a trend for increased risk among men without treatment, but this did not reach the threshold for significance (adjusted HR=2.3, 95\% CI 0.5-9.9; $\chi^{2}=1.28$, d.f. $=1, P=0.2)$.

Although similar hazard ratios were seen for the different groups of women (Table 5), the associations appeared strongest in the group of women who were depressed but not using antidepressants. In fact, in the adjusted models it was only severe depression in the absence of antidepressant treatment that significantly increased mortality risk.

We examined separately the risk associated with incident and chronic major depressive episodes, which affected $5.4 \%$ (3.7\% of men, $6.7 \%$ of women) and $4.5 \%$ ( $2.1 \%$ of men, $6.2 \%$ of women) of participants respectively (see online data supplement, Table DS1). For men with one depressive episode there was a trend for increased mortality risk; however, no such increase in risk was observed for those with recurrent depression. In women, neither incident nor recurrent episodes were significantly associated with mortality. In addition, the number of depressive episodes did not predict mortality risk in men and women when these factors where included in the multivariate models containing depression and antidepressant use (data not shown).

\section{Cause of death}

The majority of participants died from causes related to cancer (men 33\%, women $41 \%$ ) or cardiovascular disease (men 24\%, women $18 \%$ ), with fewer dying from respiratory problems (men $7 \%$, women $6 \%$ ). A substantial number died from unknown causes $(17 \%)$, which is probably the result of multiple disorders and an overall decline in general health. There were very few suicides (four in total) and only five deaths due to external causes such as accidents.

When examining a specific cause of death as the outcome variable in the multivariate adjusted Cox models (see online data supplement, Table DS2), mild depression in women significantly increased cardiac-related death. Severe depression in men resulted in an increased risk of death from all three causes that were examined (cardiac-related, tumour-related or unknown). Antidepressant treatment in men was associated with an increased risk of death from an unknown cause. The number of participants dying from other causes was too small to allow accurate analysis.

\section{Discussion}

The most striking findings of this large community-based study were the difference in depression-related mortality risk depending on whether the participants were taking antidepressants and the divergent findings across the genders. The greatest risk was for depressed men who were also antidepressant users, with increasing depression severity corresponding to a higher hazard risk. In contrast, among women it was only severe depression in the absence of treatment that significantly increased risk.

\section{Gender differences in depression-related mortality risk}

Our study suggests that the relationship between depression and mortality is not only gender-dependent but also depends on the 
Table 4 Cox proportional hazards models for the risk associated with depression or antidepressant use among elderly women $(n=4477)$

\begin{tabular}{|c|c|c|c|c|c|c|c|}
\hline & \multirow[b]{2}{*}{ Deaths $(n=165) \%$} & \multicolumn{3}{|c|}{ Unadjusted $^{\mathrm{a}}$} & \multicolumn{3}{|c|}{ Adjusted $^{\mathrm{b}}$} \\
\hline & & $\mathrm{HR}(95 \% \mathrm{Cl})$ & $\chi^{2}(\mathrm{~d} . \mathrm{f} .=1)$ & $P$ & Hazard Ratio $(95 \% \mathrm{Cl})$ & $\chi^{2}(\mathrm{~d} . \mathrm{f} .=1)$ & $P$ \\
\hline \multicolumn{8}{|l|}{ Depression severity } \\
\hline No depression & 3.2 & 1 & & & 1 & & \\
\hline Mild depression ${ }^{c}$ & 4.8 & $1.5(1.2-3.0)$ & 3.94 & 0.05 & $1.4(0.9-2.1)$ & 2.86 & 0.09 \\
\hline Severe depression ${ }^{d}$ & 5.0 & $1.6(1.1-2.4)$ & 5.02 & 0.03 & $1.4(0.9-2.2)$ & 2.95 & 0.09 \\
\hline \multicolumn{8}{|l|}{ Antidepressant use } \\
\hline No & 3.6 & 1 & & & 1 & & \\
\hline Yes & 4.7 & $1.2(0.8-2.0)$ & 0.73 & 0.4 & $1.1(0.7-1.8)$ & 0.20 & 0.7 \\
\hline \multicolumn{8}{|l|}{ Antidepressant type } \\
\hline No treatment & 3.6 & 1 & & & 1 & & \\
\hline TCAS & 1.4 & $1.7(0.8-3.9)$ & 1.81 & 0.2 & $1.7(0.7-3.7)$ & 1.45 & 0.2 \\
\hline SSRIS & 5.2 & $1.3(0.7-2.4)$ & 0.67 & 0.4 & $1.2(0.6-2.2)$ & 0.31 & 0.6 \\
\hline Other & 6.2 & $0.7(0.2-2.7)$ & 0.31 & 0.6 & $0.5(0.1-2.2)$ & 0.75 & 0.4 \\
\hline $\begin{array}{l}\text { HR, hazard ratio; SSRI, selec } \\
\text { a. Adjusted for centre. } \\
\text { b. Adjusted for centre, educ } \\
\text { c. Participants with a Cente } \\
\text { d. Participants with a curre }\end{array}$ & $\begin{array}{l}\text { euptake inhibitor; TCA, } \\
\text { us, cognitive impairment, } \\
\text { ggy Studies-Depression } \\
\text { sive disorder or a CES- }\end{array}$ & $\begin{array}{l}\text { ic antidepressan } \\
\text { alcohol consump } \\
\text { D) score }<23 \text { bi } \\
\text { re } \geqslant 23 \text {. }\end{array}$ & $\begin{array}{l}\text { egular smoking } \\
\text { ve the cut-off } f\end{array}$ & $\begin{array}{l}\text { ability, re } \\
\text { inically }\end{array}$ & $\begin{array}{l}\text { nt hospitalisation, comorbidity } \\
\text { ificant depressive symptom }\end{array}$ & $\begin{array}{l}\text { l, underweight } \\
s(\geqslant 16) \text {. }\end{array}$ & obesity. \\
\hline
\end{tabular}

Table 5 Cox proportional hazards models for the combined effect of depression severity with or without antidepressant treatment, separately in elderly men $(n=2886)$ and women $(n=4477)$

\begin{tabular}{|c|c|c|c|c|c|c|c|}
\hline \multirow[b]{2}{*}{ Variables } & \multirow[b]{2}{*}{ Deaths \% } & \multicolumn{3}{|c|}{ Unadjusted $^{a}$} & \multicolumn{3}{|c|}{ Fully Adjusted ${ }^{\mathrm{b}}$} \\
\hline & & $\mathrm{HR}(95 \% \mathrm{Cl})$ & $\chi^{2}($ d.f. $=1)$ & $P$ & $\mathrm{HR}(95 \% \mathrm{Cl})$ & $\chi^{2}($ d.f. $=1)$ & $P$ \\
\hline \multicolumn{8}{|l|}{ Men } \\
\hline \multicolumn{8}{|l|}{ Depression and antidepressant use } \\
\hline No depression/no antidepressant & 6.5 & 1 & & & 1 & & \\
\hline No depression/uses antidepressants & 13.1 & $1.6(0.8-3.3)$ & 1.68 & 0.2 & $1.3(0.6-2.7)$ & 0.41 & 0.5 \\
\hline Mild depression/no antidepressant & 10.2 & $1.4(0.9-2.2)$ & 2.15 & 0.1 & $1.3(0.9-2.1)$ & 1.57 & 0.2 \\
\hline Mild depression/uses antidepressants & 21.1 & $3.0(1.1-8.2)$ & 4.66 & 0.03 & $2.8(1.0-7.7)$ & 4.03 & 0.04 \\
\hline Severe depression/no antidepressant & 10.3 & $1.9(1.1-3.5)$ & 4.84 & 0.03 & $1.8(1.0-3.3)$ & 3.57 & 0.06 \\
\hline Severe depression/uses antidepressants & 35.3 & $6.5(3.4-12.5)$ & 32.41 & $<0.001$ & $5.3(2.7-10.5)$ & 23.64 & $<0.001$ \\
\hline \multicolumn{8}{|l|}{ Women } \\
\hline \multicolumn{8}{|l|}{ Depression and antidepressant use } \\
\hline No depression/no antidepressant & 3.1 & 1 & & & 1 & & \\
\hline No depression/uses antidepressants & 5.9 & $1.6(0.8-3.1)$ & 2.01 & 0.2 & $1.5(0.8-2.9)$ & 1.54 & 0.2 \\
\hline Mild depression/no antidepressant & 4.7 & $1.5(1.0-2.3)$ & 3.38 & 0.07 & $1.4(0.9-2.2)$ & 2.46 & 0.1 \\
\hline Mild depression/uses antidepressants & 5.4 & $2.2(0.8-6.0)$ & 2.34 & 0.1 & $2.0(0.7-5.4)$ & 1.77 & 0.2 \\
\hline Severe depression/no antidepressant & 5.6 & $1.9(1.2-3.0)$ & 8.21 & 0.004 & $1.8(1.1-2.8)$ & 6.18 & 0.01 \\
\hline Severe depression/uses antidepressants & 2.9 & $0.9(0.3-2.5)$ & 0.04 & 0.8 & $0.8(0.3-2.1)$ & 0.33 & 0.6 \\
\hline
\end{tabular}

severity of depression. The findings of increased mortality risk among certain subgroups remained significant even after controlling for a large number of variables, including several measures of health status. Therefore our results do not support the suggestion that declining health explains in large part the association between depression and mortality. ${ }^{14}$

It has been reported that increasing depressive symptoms ${ }^{8,25}$ are associated with incrementally higher mortality risk; however, from our gender-stratified analysis we found that this was only the case for men. In women the overall association between depression and mortality was less marked, with non-significant adjusted associations and no apparent increase according to depression severity. These gender variations could be the consequence of differences in the nature or intensity of exposure to risk factors, or in the susceptibility to the same risk factors. They could result from cultural, social, behavioural or adaptive differences. Women tend to report a greater number of symptoms and a higher degree of distress ${ }^{26}$ and may differ from men in their perceived need and willingness to seek treatment. Depression is less likely to be recognised in $\operatorname{men}^{27}$ and therefore the presence of detectable depressive symptoms in elderly men could also signify a more extreme condition, ${ }^{28}$ which might account for the stronger associations with mortality, even for mild depression. Another possibility is that in older people with depression, men are more likely to die and women to be first disabled. This hypothesis could be tested with a longer follow-up period.

Our finding that incident depression - but not chronic depression - increases mortality risk in men only, has been reported previously. ${ }^{6}$ However, our study suggests that this factor is secondary to the association between depression severity and/or antidepressant use, as it was not significantly associated with 4-year survival 
when included in the models presented. It should be noted, however, that there was a higher rate of missing data regarding previous episodes in currently depressed participants, and therefore this finding requires further validation.

\section{Gender differences in antidepressant-related mortality risk}

Despite our finding that antidepressant use in depressed men was associated with increased mortality risk, no such association was found in non-depressed men who used antidepressants, arguing against the pharmacological adverse effects of the antidepressants as a potential cause. Assuming that these treated participants were formerly depressed, this would indicate rather that adequate treatment of depression results in a reduction in the increased mortality rate. Likewise, the presence of depressive symptoms despite treatment could be an indication of depression severity, rather than non-efficacy of treatment, and therefore this increased depression severity could account for the higher mortality risk among this group.

In quite a different manner, only women with untreated severe depression had an increased risk, suggesting a positive impact of treatment even in women with residual symptoms. These results could highlight gender differences in the prescription and use of antidepressants, or in treatment adherance. It might also be that women respond better to specific types of antidepressant treatment than men, ${ }^{29}$ although this has rarely been reported in the case of post-menopausal women, and therefore depressed women receiving treatment may be better off than their male counterparts. Even when individuals respond to antidepressant treatment, they can still maintain clinically diagnosable depression. ${ }^{28}$ The treatment may be effective but need to be given for a longer period, or the depression may be resistant to treatment. This raises the question of the dosage and/or reduction in depression symptoms required for both men and woman. Overall, these results emphasise the importance of stratifying the analysis by gender, with clear gender differences in mortality risks.

Interestingly, we found no significant difference in mortality risk when we compared the different types of antidepressants, despite suggestions that SSRIs and tricyclic antidepressants have differential effects on cardiovascular health. ${ }^{30}$ Benzodiazepinerelated medications, which are used to treat anxiety and are often administered in combination with or in place of antidepressants, ${ }^{31}$ were not associated with mortality risk in either men or women. In addition, this factor did not confound the associations reported here (data not shown).

\section{Why is depression associated with increased mortality?}

The relationship between depression and mortality is thought to result from a combination of factors. Depression appears to exacerbate the outcome of medical illness, ${ }^{1}$ even in appropriately adjusted analysis, and it is possible that depression acts as a proxy marker for the severity of physical ill health. Psychological wellbeing also has a role, with loss of motivation and social isolation enhancing the effect of depression on mortality. ${ }^{32}$ Finally, several behavioural mechanisms could help explain the risk associated with depression. Participants who are depressed are less likely to adhere to their medication regimen, ${ }^{7,33}$ affecting other illnesses they might have. They may also behave in ways that are detrimental to their overall health, particularly men; ${ }^{33}$ however, the associations found in this analysis remained even after controlling for 'self-care' variables (smoking, alcohol, BMI). Further work is needed to determine why the prognosis of depression appears to differ between men and women and why it is worse among male antidepressant users.

\section{Cause of deaths}

Our results showed that the increased mortality risk associated with severe depression in men was in part due to an increase in cardiac-related mortality, as reported previously. ${ }^{7}$ In women mild but not severe depression appeared to increase cardiac death. Men with severe depression had an increased risk of death from 'unknown' causes, which could reflect the helplessness of severely depressed men, who might just give up on life and die from multiple conditions and dwindling health. Other studies have suggested that depression and antidepressant use increase the risk of suicide $^{34}$ and may increase deaths by unnatural causes such as accidents, particularly among men. However, as found in other community-based studies of older people, external causes of death were rare in our population. ${ }^{4}$

\section{Limitations}

This study has several limitations. The data concerning some of the covariates were self-reported, which may be subject to recall bias with depressed participants responding more negatively about their health. However, as these self-report measures concern the covariates, and since similar associations were seen in the unadjusted and adjusted analysis, it would appear that any bias did not have a substantial influence on the results. Bias could also be introduced from the exclusion of participants with missing data, who were more likely to be depressed, or from the participants lost to follow-up, who were more likely to have died. Thus, people with the strongest potential depression-mortality association might have been selectively excluded, so that associations between depression and mortality were underestimated. Assessment of depression and collection of information on antidepressant use took place at inclusion and therefore the status of these participants at the time of their deaths is unknown. In addition, we did not consider treatment adherance, which might have caused classification bias, or the history and duration of antidepressant use, which might have influenced the results. In particular, for men it would be interesting to assess whether there was a differential effect of short-term $v$. long-term antidepressant treatment on mortality. Finally, it is possible that there are other unknown factors, including subclinical disease (in addition to that detectable through the analysis of lipids, glycaemia and hypertension), that might confound the association between depression and mortality.

\section{Strengths}

The study has a number of strengths. The data used in the analysis come from a large, multicentre, population-based prospective study of people aged 65 years and over. Depression was assessed by trained staff using two distinct measures validated in the general population, including a structured diagnostic interview, ${ }^{16,18}$ and antidepressant use was verified by examining the prescriptions and medications themselves, thus minimising exposure misclassification. In addition, by using a large community sample we were able to cover a wide range of depression profiles, from subclinical symptoms to major depression, thus addressing the problem of the variety of definitions of depression in previous research. In this study we obtained comprehensive information on the mortality status of the participants, using death registries and medical records, with only nine participants lost to follow-up. We controlled for a large number of covariates, particularly measures of physical health (comorbidity, physical incapacities, recent hospitalisation, health behaviours) and cognitive impairment, that reportedly explain in large part the reported depression-mortality 
link. ${ }^{13,14}$ Despite this, there were only minor changes in the hazard ratios between the unadjusted and adjusted analyses, suggesting independence of associations. Finally, in contrast to the majority of community-based studies, we have explored the role of antidepressants in the depression-mortality association, which enabled us to better characterise the profile of the elderly participants who are most at risk of dying.

Our findings suggest that the relationship between depression and mortality in older populations is gender-dependent and also varies according to symptom load. This association is modified when the use of antidepressants is also taken into consideration, which indicates the importance of including this factor when investigating mortality risk. Findings from this study suggest an increased risk of mortality for men with even subclinical depression and highlight the importance of detecting depressive symptoms, most notably by the general practitioner during routine medical visits. This study suggests that inadequate treatment of late-life depression may reduce long-term survival and that resistance to treatment in men could have a detrimental effect on their survival.

Joanne Ryan, MSC, Isabelle Carriere, PhD, Karen Ritchie, PhD, Institut National de la Santé et de la Recherche Médicale (INSERM) U888, University of Montpellier, France; Robert Stewart, MD, PhD, INSERM U888, Montpellier, France and King's College London, Institute of Psychiatry, London, UK; Gwladys Toulemonde, MSC, INSERM U888, University of Montpellier; Jean-François Dartigues, MD, PhD, INSERM U593, University of Bordeaux; Christophe Tzourio, MD, PhD, INSERM U708, University of Paris; Marie-Laure Ancelin, PhD, INSERM U888, University of Montpellier, France.

Correspondence: Dr Marie-Laure Ancelin, INSERM U888, Nervous System Pathologies, Hôpital La Colombière, P42, 34093 Montpellier Cedex 5, France. Email: ancelin@montp.inserm.fr

First received 19 April 2007, final revision 10 July 2007, accepted 15 August 2007

\section{Acknowledgements}

We thank the Génopôle of Lille, the Laboratories of Biochemistry of the University Hospitals of Dijon (Professor Gambert) and Montpellier (Dr Dupuy), the Town Council of Dijon, the Conseil Général of Côte d'Or and the clinical case validation committee of the $3 \mathrm{C}$ Study. J.R. is the recipient of a France Alzheimer grant.

\section{References}

1 Alexopoulos GS. Depression in the elderly. Lancet 2005; 365: 1961-70.

2 Unutzer J. Diagnosis and treatment of older adults with depression in primary care. Biol Psychiatry 2002; 52: 285-92.

3 Tiemeier $\mathrm{H}$, Breteler MM, Hofman A, Stijnen T. A multivariate score objectively assessed health of depressed elderly. J Clin Epidemiol 2005; 58: 1134-41.

4 Penninx BW, Geerlings SW, Deeg DJ, van Eijk JT, van Tilburg W, Beekman AT Minor and major depression and the risk of death in older persons. Arch Gen Psychiatry 1999; 56: 889-95.

5 Schulz R, Beach SR, Ives DG, Martire LM, Ariyo AA, Kop WJ. Association between depression and mortality in older adults: the Cardiovascular Health Study. Arch Intern Med 2000; 160: 1761-8.

6 Anstey KJ, Luszcz MA. Mortality risk varies according to gender and change in depressive status in very old adults. Psychosom Med 2002; 64: 880-8.

7 Vinkers DJ, Stek ML, Gussekloo J, Mast RC van der, Westendorp RG. Does depression in old age increase only cardiovascular mortality? The Leiden 85 plus Study. Int J Geriatr Psychiatry 2004; 19: 852-7.

8 Adamson JA, Price GM, Breeze E, Bulpitt CJ, Fletcher AE. Are older people dying of depression? Findings from the Medical Research Council trial of the assessment and management of older people in the community. J Am Geriatr Soc 2005; 53: 1128-32.

9 Thomas C, Kelman HR, Kennedy GJ, Ahn C, Yang C. Depressive symptoms and mortality in elderly persons. J Gerontol 1992; 47: S80-7.

10 Callahan CM, Wolinsky FD, Stump TE, Nienaber NA, Hui SL, Tierney WM. Mortality, symptoms, and functional impairment in late-life depression. J Gen Intern Med 1998; 13: 746-52.
11 Cuijpers P. Mortality and depressive symptoms in inhabitants of residentia homes. Int J Geriatr Psychiatry 2001; 16: 131-8.

12 Hybels CF, Pieper CF, Blazer DG. Sex differences in the relationship between subthreshold depression and mortality in a community sample of older adults. Am J Geriatr Psychiatry 2002; 10: 283-91.

13 McCusker J, Cole M, Ciampi A, Latimer A, Windholz S. Does depression in older medical inpatients predict mortality? J Gerontol A Biol Sci Med Sci 2006; 61: 975-81.

14 Blazer DG, Hybels CF, Pieper CF. The association of depression and mortality in elderly persons: a case for multiple, independent pathways. J Gerontol Biol Sci Med Sci 2001; 56: M505-9.

15 The $3 \mathrm{C}$ Study Group. Vascular factors and risk of dementia: design of the three city study and baseline characteristics of the study population. Neuroepidemiol 2003; 22: 316-25.

16 Sheehan DV, Lecrubier $\mathrm{Y}$, Sheehan $\mathrm{KH}$, Amorim $\mathrm{P}$, Janavs J, Weiller $\mathrm{E}$, Hergueta T, Baker R, Dunbar GC. The Mini-International Neuropsychiatric Interview (MINI): the development and validation of a structured diagnostic psychiatric interview for DSM-IV and ICD-10. J Clin Psychiatry 1998; 59 Supp 20: 22-33; quiz: 34-57.

17 American Psychiatric Association. Diagnostic and Statistical Manual of Mental Disorders (4th edn) (DSM-IV). APA, 1994.

18 Radloff LS. The CES-D scale: a self-report depression scale for research in the general population. Appl Psychol Meas 1977; 1: 385-401.

19 World Health Organization. World Health Organising Collaborating Centre for Drug Statistics Methodology. Guidelines for ATC Classification and DDD assignment. WHO, 2000.

20 World Health Organization. International Statistical Classification of Diseases and Related Health Problems (ICD-10). WHO, 1992.

21 Lawton MP, Brody EM. Assessment of older people: self-maintaining and instrumental activities of daily living. Gerontologist 1969; 9: 179-86.

22 Katz S, Ford AB, Moskowitz RW, Jackson BA, Jaffe MW. Studies of illness in the aged. The index of adl: a standardised measure of biological and psychosocial function. JAMA 1963; 185: 914-19.

23 Folstein MF, Folstein SE, McHugh PR. "Mini-mental state." A practical method for grading the cognitive state of patients for the clinician. $J$ Psychiatr Res 1975; 12: 189-98.

24 Commenges D, Letenneur L, Joly P, Alioum A, Dartigues JF. Modelling agespecific risk: application to dementia. Stat Med 1998; 17: 1973-88.

25 Wulsin LR, Evans JC, Vasan RS, Murabito JM, Kelly-Hayes M, Benjamin EJ. Depressive symptoms, coronary heart disease, and overall mortality in the Framingham Heart Study. Psychosom Med 2005; 67: 697-702.

26 Kornstein SG, Sloan DM, Thase ME. Gender-specific differences in depression and treatment response. Psychopharmacol Bull 2002; 36: 99-112.

27 Crawford MJ, Prince $M$, Menezes $\mathrm{P}$, Mann $\mathrm{AH}$. The recognition and treatment of depression in older people in primary care. Int J Geriatr Psychiatry 1998; 13: $172-6$

28 Gorman JM. Gender differences in depression and response to psychotropic medication. Gend Med 2006; 3: 93-109.

29 Khan A, Brodhead AE, Schwartz KA, Kolts RL, Brown WA. Sex differences in antidepressant response in recent antidepressant clinical trials. J Clin Psychopharmacol 2005; 25: 318-24.

30 Cohen HW, Gibson G, Alderman MH. Excess risk of myocardial infarction in patients treated with antidepressant medications: association with use of tricyclic agents. Am J Med 2000; 108: 2-8.

31 Van Rijswijk $E$, Borghuis $M$, van de Lisdonk $E$, Ziman $F$, Van Weel $C$. Treatment of mental health problems in general practice: a survey of psychotropics prescribed and other treatments provided. Int J Clin Pharmacol Ther 2007; 45: 23-9.

32 Stek ML, Vinkers DJ, Gussekloo J, Beekman ATF, van der Mast RC, Westendorp RG. Is depression in old age fatal only when people feel lonely? Am J Psychiatry 2005; 162: 178-80.

33 Ciechanowski PS, Katon WJ, Russo JE. Depression and diabetes: impact of depressive symptoms on adherence, function, and costs. Arch Intern Med 2000; 160: 3278-85.

34 Kivimaki M, Gunnell D, Lawlor DA, Davey Smith G, Pentti J, Virtanen M Elovainio M, Klaukka T, Vahtera J. Social inequalities in antidepressant treatment and mortality: a longitudinal register study. Psychol Med 2006; 36 $1-10$

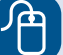

